\title{
Informação e políticas públicas: responsabilidade social da Ciência da Informação
}

\author{
Marcia Mazo Santos \\ Tribunal Regional Federal da Primeira Região - Brasil \\ Jair Cunha Cardoso Filho \\ Universidade de Brasília - Brasil
}

ANÁLISE / ANALYSIS

\begin{abstract}
Resumo
Apresenta os fundamentos teóricos da $\mathrm{Cl}$ a partir da inserção do tema responsabilidade social em seu contexto. Discorre sobre os conceitos de políticas públicas e argumenta como a vertente social da ciência da informação contribui no estabelecimento de políticas públicas. Adota a definição de Borko para a $\mathrm{Cl}$, e apresenta o que é entendido por informação como suporte à tomada de decisão, particularmente no que se refere ao estabelecimento de políticas públicas. Comenta sobre o ciclo das políticas públicas e a tipologia de políticas públicas de Lowi, e demonstra que ferramentas da $\mathrm{Cl}$ são recursos legítimos para integrar e coordenar a heterogeneidade dos recursos informacionais existentes em uma sociedade para, por meio de políticas públicas, permitirem ao ser humano construir a si mesmo e o seu mundo, de forma livre e autônoma, e transformar a realidade na direção do desenvolvimento político, econômico e social.
\end{abstract}

Palavras-chave

Ciência da Informação ; Responsabilidade social ; Políticas públicas

\section{Information and public policy: social responsibility of Information Science}

\begin{abstract}
Presents the theoretical foundations of information science - IS from the insertion of the subject in its social responsibility context. Discusses the concepts of IS related with social responsibility and public policies. Argues how parts of the IS contributes to the establishment of public policies. Adopts the definition of Borko for IS, and presents what is known as information as support of decision making, particularly with regard to the establishment of public policies. Comments on the cycle of public policy and the typology of Lowi's public policies, and demonstrates that the IS tools are legitimate resources to integrate and coordinate the heterogeneity of information resources that exist in a society, through public policies, to allow human beings to build themselves and your own world, freely and autonomously, and transform reality in the direction of political, economic and social development.
\end{abstract}

Keywords

Information Science ; Social responsibility ; Public policies 


\section{Introdução}

A ciência da informação - $\mathrm{Cl}$ é um campo multifacetado. Seu objeto de estudo é a informação em uma determinada área ou sob determinada abordagem. Caracterizada desde sua origem como interdisciplinar, abrange um largo espectro de possibilidades temáticas de estudiosos de diferentes formações acadêmicas e, consequentemente, como campo de pesquisa apresenta riqueza de abordagens.

Considerando sua interdisciplinaridade, a abordagem deste artigo é voltada para a responsabilidade social da $\mathrm{Cl}$ no sentido de contribuir com a tomada de decisão no estabelecimento de políticas públicas para a transformação daquilo que é do âmbito privado, em ações coletivas no espaço público.

No contexto das políticas públicas, também é necessária uma visão integrada, pois um projeto de políticas públicas, obrigatoriamente, deve permitir a interdisciplinaridade ou multidisciplinaridade.

Assim, nosso caminho começa a ser desenhado ainda no século XIX, com Paul Otlet, quando começam as primeiras preocupações com a responsabilidade social da informação. Em seguida, apresentamos a preocupação de Suzanne Briet com a disponibilização da informação, em seu tratado sobre a documentação para, então, introduzirmos os primeiros conceitos de responsabilidade social da $\mathrm{Cl}$ abordados por Wersig e Neveling, Ingwersen, Barreto, Saracevic, Bates, Ørom, Araújo, Capurro, Zins. A partir dessa fundamentação teórica, abordaremos a disciplina das políticas públicas e a contribuição de Lowi e Souza para o campo.

\section{Traçado histórico da Ciência da Informação}

Naudé, em 1627 e Otlet, em 1834, ressaltaram uma dimensão humana e libertária do acesso à informação pública que soa extremamente atual no início do século XX (SMIT et al. 2004).

Após a segunda guerra mundial, com o desenvolvimento científico e tecnológico ocorrido ante e pós-guerra, começam as preocupações com a recuperação dessa informação. Mas é na década de 1960 que acontecimentos como a conferência realizada no Georgia Institute of Technology em 1962, o Relatório Weinberg em 1963, o trabalho Informatik de Mikhailov, em 1966, a definição de Borko em seu artigo Information Science: what is it? de 1968, indicam o nascimento de uma nova ciência, e aparecem os primeiros artigos abordando os conceitos, fundamentos, e teorias sobre a Cl.

Uma nova disciplina surge porque novas relações aparecem com outros campos.

$\mathrm{A} \mathrm{Cl}$ está fortemente relacionada com outras áreas, como a tecnologia da informação, a matemática, estatística, filosofia, taxonomia, lingüística e tantas outras.

Inferindo que informação é o registro de um conhecimento, e que de acordo com Popper (1972) a ciência não é um fim, e sim uma busca pela "verdade", a ciência da informação está percorrendo esse caminho conturbado de conceitos contestados, complementados e questionados, mas que tem fundamentação para ser exercida na prática envolvendo o fluxo da informação desde a sua origem ao seu uso, passando pelos primórdios com os processos explicitados por Borko (1968), sua utilização advinda da necessidade social conforme Wersig e Neveling (1975), e com conceitos trazidos e analisados por Belkin (1993),

Nasce como uma ciência pós-moderna, mais flexível, que sabe que nenhuma forma de conhecimento é em si mesma racional, mas dialoga com outras formas de conhecimento deixando-se penetrar por elas, superando a crise do paradigma desde o século XVII, bem como a racionalidade cartesiana (SANTOS, 1988). Wersig (1993) salienta que a ciência da informação é pós-moderna por considerar o seu campo caótico, por falta de um objeto e de um método únicos, mas traz Feyerabend para comentar que a ciência pós-moderna não tem um único e específico método a ser aplicado, mas qualquer método que funcione. Nesse contexto se inclui a $\mathrm{Cl}$, por ser um campo inter e multidisciplinar, trabalhando com estratégias para solução de problemas relacionados ao novo papel e uso do conhecimento, o que requer uma nova ciência, não clássica, mas inovadora. 


\section{O conceito de Ciência da Informação}

Para delimitar nosso campo de estudo, adotaremos a definição de Borko (1968) para a Cl, sem entrar nas perspectivas histórico-metodológicas nem discussões epistemológicas ou paradigmáticas da disciplina em si:

[...] uma ciência interdisciplinar que estuda as propriedades e o comportamento da informação, as forças que dirigem o fluxo e o uso da informação e as técnicas, tanto manuais como mecânicas, de processar a informação visando sua armazenagem, recuperação e disseminação. (BORKO, 1968, p. 3, tradução nossa).

De acordo com Tarapanoff (2006), no campo da Cl o conceito de informação é utilizado no sentido de conhecimento comunicado, desenvolvido após a segunda guerra mundial, e que adotaremos ao abordarmos sobre informação.

Paul Otlet, belga nascido em 1868, advogado, desde cedo se preocupou em oferecer um sistema de armazenamento com a condensação universal de todos os dados fragmentados e individuais de todos os ramos das ciências, constantemente atualizados, para que todo o mundo pudesse ter acesso ao conhecimento, o que poderia estabelecer a paz mundial. Uma rede com links distribuidores entre os centros de produção e os usuários, por meio da qual qualquer pessoa possuidora de dados, informação ou conhecimento a ser comunicado seria capaz de fazêlo e, ao mesmo tempo, com um mínimo de esforço e uma garantia de segurança e qualidade, seria capaz de recuperá-lo. Junto com seu amigo Henri La Fontaine, criou a Classificação Decimal Universal - CDU, que era muito mais que um método para organizar livros nas estantes: esperavam criar a base da documentação, uma linguagem universal para a ciência - os números.

Otlet queria que todos os livros ou artigos trouxessem o número da CDU correspondente ao assunto daquele documento, o que serviria como meio de comunicação e de relacionamento entre os cientistas do mundo (LEVIE, 2002).

Segundo Fayet-Scribe (2001):

[...] e a própria documentação caíram no esquecimento, pois a proximidade da Segunda Guerra Mundial deflagrou um momento pouco propício para as utopias pacifistas em que se pautava a cooperação internacional necessária à elaboração de instrumentos de acesso ao conhecimento registrado [...] a visão otletiana de uma economia intelectual em um espaço informacional internacional [...] (Citado por ORTEGA, 2009, p. 66).

Após a segunda guerra mundial houve uma grande busca pela informação científica, tanto do lado ocidental quanto do oriental. Na corrente oriental, destacamos os esforços de Mikhailov, Chernyi e Gilyarevskii que se dedicaram à criação de uma disciplina Informatik, e do lado ocidental destacamos a preocupação com o armazenamento e recuperação da informação.

Vale ressaltar que essa preocupação era de químicos, físicos, matemáticos, biólogos, daí se intitularem cientistas da informação para não perderem o status acadêmico em suas áreas respectivas.

Em 1951, Suzanne Briet, nascida em Paris em 1894, discípula de Otlet, escreve Qu'est-ce que la documentation?, onde define documentação como sendo

[...] todo indício concreto ou simbólico, conservado ou registrado, com o fim de representar, reconstruir ou provar um fenômeno físico ou intelectual, baseada no entendimento sociológico e cultural das necessidades dos usuários, expressas por seus modos de vida e seu vocabulário. A documentação é uma técnica de trabalho intelectual, é uma profissão distinta, e uma necessidade de nossos tempos. O documento não é mais caracterizado pelo seu suporte, mas pela sua condição de registro que garante a permanência no tempo, e que pode estar em qualquer lugar, e acessado por qualquer pessoa, para isso o documentalista teria que conhecer outras línguas para garantir que a tradução de um documento fosse de alta qualidade para que o usuário pudesse compreender o assunto. (BRIET, 1951, p.26).

A responsabilidade social da $\mathrm{Cl}$ toma força quando, depois das discussões sobre organização da documentação científica, aparecem as inquietações sobre a transferência dessa informação. 
Em 1975, quando Wersig e Neveling abordam os fenômenos de interesse para a Cl, entre eles está o problema de transferência do conhecimento para aqueles que dele necessitam. Para esses autores, isso é "uma responsabilidade social e esta responsabilidade social parece ser o motivo real da ciência da informação".

\section{Responsabilidade social da Ciência da Informação}

Borko (1968) posiciona a Cl como um campo novo, como uma disciplina que tem uma função social de auxiliar o desenvolvimento das demais ciências por meio da melhoria dos processos de comunicação, disseminação e compartilhamento do conhecimento. Os campos de pesquisa sugeridos pelo autor são atuais e ainda hoje perseguidos, daí a desejável diversidade de contribuições de diferentes opiniões nesse contexto de pesquisa, e o reforço à sua dimensão de ciência inter e multidisciplinar.

Com uma abordagem também epistemológica, Wersig e Neveling (1975), concordam com Borko (1968) quando afirmam que a $\mathrm{Cl}$ é um campo novo e interdisciplinar de estudo que surgiu a partir das exigências de uma área de trabalho prático, e que seu nascimento é fruto da contribuição de diversas disciplinas distintas, de pessoas de diversas formações e diferentes interesses, mas vinculados ao estudo dos processos de criação, armazenamento, recuperação e disseminação da informação em suas diversas áreas do conhecimento.

Wersig e Neveling (1975) afirmam que a Cl deve servir para o preenchimento de determinadas necessidades sociais (visão orientada para os fins) e que sua responsabilidade social se dá na medida em que possibilita a transferência do conhecimento para aqueles que dele necessitam sugerindo, portanto, apoio à sociedade.

Esses autores abordam pela primeira vez a responsabilidade social da $\mathrm{Cl}$ ao perguntarem: Que exigências sociais devem ser atendidas pela ciência da informação? Para eles o problema começou com a invenção da imprensa por Gutenberg, tornando possível a disseminação da informação primária para um público maior. Em seguida, surgiram as fontes secundárias de informação que traziam resumos de artigos científicos. Com a crescente publicação de artigos científicos de um lado e, do outro, o público interessado em acessar essa informação há uma busca pelo profissional da informação, não mais o bibliotecário, responsável pela guarda do conhecimento, mas aquele profissional que vai fazer a intermediação entre a informação armazenada e o usuário que necessita dela:

Hoje, o problema da transferência do conhecimento para aqueles que dele necessitam é uma responsabilidade social e esta responsabilidade social parece ser o motivo real da "ciência da informação" (WERSIG; NEVELING, 1975, p. 11. Traduzido por Tarcísio Zadonade).

Ingwersen (1992, p.14), por sua vez, aborda a possibilidade de cooperação entre a tecnologia e a esfera humana com relação à transferência da informação, uma abordagem prático-disciplinar para a $\mathrm{Cl}$ e uma visão apontando para seu futuro:

[...] uma mudança de compreensão das informações como puramente científica para informação concebida no sentido amplo, como um recurso crítico e estratégico para indivíduos e sociedade [….(INGWERSEN, 1992, p.14, tradução nossa).

De acordo com o autor, a $\mathrm{Cl}$ tem duas grandes tendências, uma que permeia a comunicação, e outra a informática. A comunicação aparece na transferência do conhecimento registrado, e a informática com os sistemas e aplicação da tecnologia da informação para organização e transferência do conhecimento.

A Cl deve ser estudada levando em consideração a geração, comunicação e utilização da informação. Na opinião de Ingwersen (1992), é extremamente relevante a noção de "informação desejada". A ênfase está na qualidade da interação entre geradores e usuários da informação registrada.

Barreto (1994, p.3), em suas reflexões, interessado no fenômeno da informação entre seres humanos que habitam um determinado espaço social, político e econômico, também segue na direção da responsabilidade social da $\mathrm{Cl}$, quando afirma que:

A importância que a informação assumiu na atualidade pós-industrial recoloca para o pensamento questões sobre a sua natureza, seu conceito e os benefícios que pode trazer ao indivíduo e no seu relacionamento com o mundo em que vive. [...] A informação, quando adequadamente assimilada, produz conhecimento e modifica o estoque mental de significados do indivíduo, traz benefícios ao 
seu desenvolvimento e ao progresso da sociedade em que ele vive. Assim, como agente mediador na produção do conhecimento, a informação qualifica-se, em forma e substância, como sendo: o conjunto de estruturas significantes com a competência de gerar conhecimento para o indivíduo e seu grupo (BARRETO, 1994, p.3).

Saracevic (1995) é categórico ao estabelecer três características para a Cl: a) é interdisciplinar; b) está, inexoravelmente, ligada à tecnologia da informação; e c) tem uma forte dimensão social e humana, acima e além da tecnologia. Bush (1945, citado por Saracevic, 1995) alertou para a necessidade de se encontrar uma forma de se fazer uso apropriado do grande volume que estava sendo gerado durante e após a segunda guerra mundial. Informação que seria relevante para muitos, mas poucos tinham acesso, era preciso uma solução tecnológica para armazenar e recuperar essa explosão de informação.

Explosão da informação é um problema social que começou na ciência, e agora se espalhou para todo o conhecimento humano [...] investimentos em sistemas modernos de recuperação da informação [...].Sim, eles envolvem grandes doses de tecnologia, mas a sua importância se relaciona a questões e problemas humanos e sociais (SARACEVIC, 1995, p.2, tradução nossa).

Saracevic, em artigo de 1996, reafirma a forte interdisciplinaridade entre a $\mathrm{Cl}$, a biblioteconomia, a ciência da computação, a ciência cognitiva e a comunicação social para justificar a dimensão humana, o papel social e a responsabilidade social da $\mathrm{Cl}$. Ressalta os papeis econômico e social das atividades de informação em direção ao desenvolvimento nacional e ao progresso social, e que o equilíbrio homem-tecnologia precisa originar-se do seu lado humano. Aborda que os problemas da $\mathrm{Cl}$, por sua interdisciplinaridade, devem ser enfocados em termos humanos e não tecnológicos, e ao enfatizar a importância da tecnologia e a influência das atividades de informação para o desenvolvimento econômico e social das nações, concorda com Wersig e Neveling (1975) quanto à responsabilidade social da $\mathrm{Cl}$, fortalecendo a ideia de que fazer chegar o conhecimento a quem dele necessita é o verdadeiro fundamento da $\mathrm{Cl}$.

A necessidade de rever os conceitos de $\mathrm{Cl}$ é abordada por Bates (1999) que faz uma analogia de explícito e implícito, com o que está acima e abaixo do nível da água. $\mathrm{Na} \mathrm{Cl}$, o que está explícito, ou acima do nível da água, já foi bastante discutido: coleta, organização, armazenagem, e disseminação da informação. $O$ que deve ser estudado agora é o que está abaixo desse nível: as atividades mentais do profissional para a representação e organização da informação, e o papel da $\mathrm{Cl}$ como uma meta-ciência que vai estudar e desenvolver teorias para todas as áreas trazendo algo de valor para a sociedade.

Para Bates (1999), a Cl transita por várias disciplinas científicas, como a educação (ensinado e aprendendo) e o jornalismo (com a descoberta e transmissão de notícias). Por isso, a $\mathrm{Cl}$ deve se preocupar com a informação como um fenômeno social e psicológico. O foco principal está na informação registrada e como as pessoas se relacionam com ela. A informação registrada vai além das pesquisas científicas, como literatura, música, filme, etc.

O domínio da ciência da informação é o universo da informação registrada que é selecionado e retido para posterior acesso: o domínio da educação é o currículo, e o domínio do jornalismo é o produto jornalístico de todas as áreas de interesse (relatórios científicos, políticos, etc.). Note que em cada caso, o produto intelectual da pesquisa ou das atividades sociais e culturais é selecionado, projetado e formatado para alguma proposta social (BATES, 1999, p.1044, tradução nossa).

Bates (1999) acredita que o produto das atividades humanas, e como as pessoas procuram, recuperam e usam a informação é o domínio intelectual da Cl. Ela deve responder a três grandes questões: a) a questão física: quais são os aspectos e leis do universo da informação registrada; b) a questão social: como as pessoas se relacionam com a informação; c) questão do desenho: como o acesso à informação registrada pode ocorrer de maneira mais rápida e efetiva.

Ørom (2000), por sua vez, informa que as instituições de informação/bibliotecas e a Cl foram desafiadas pelas mudanças sociais que foram acontecendo e, desde 1934, Ortega y Gasset traça a missão da biblioteca e do bibliotecário em um contexto social e histórico, onde o foco é a necessidade do livro. Na Idade Média, o livro não era para uso público, essa concepção da necessidade do livro aparece no Renascimento, ao mesmo tempo em que o 
bibliotecário aparece como uma categoria social. No século XIX, há uma preocupação com a promoção da leitura, que seria essencial para o desenvolvimento de uma sociedade democrática.

As concepções de mudança na estrutura e no conteúdo da disciplina foram determinadas pelas mudanças nas funções sociais das instituições de informação, na produção e comunicação do conhecimento, e por teorias interdisciplinares, ou teorias assumidas de outras disciplinas. (ØROM, 2000, p.14, tradução nossa).

Traçando a história da Cl, que é institucionalizada nos anos de 1960 e tem seu foco na recuperação da informação, Ørom (2000) percebe que a Cl deve ser vista por uma perspectiva holística e interdisciplinar. Ressalta que 0 contexto social é especialmente relevante para a $\mathrm{Cl}$ por dois motivos: o primeiro é que o seu objeto está sujeito a mudanças históricas, e o segundo é que a análise da disciplina por uma perspectiva científica é valiosa para o entendimento da sua natureza. Reforçando que as mudanças de concepção da estrutura e do conteúdo da disciplina foram determinadas pelas mudanças sociais, o autor apresenta algumas abordagens: concepção pré-guerra, vendo a biblioteca como uma instituição social; aspectos pós-guerra, trazendo uma visão cognitiva; paradigma físico: a recuperação da informação; a escola cognitiva, que diz que o conhecimento é relativo na medida em que é alterado por processos cognitivos e sociais.

Araújo (2003, p.26-27) traz como argumentos os três grandes modelos teóricos das ciências sociais (positivista funcionalista, dialético, estruturalista) e sua influência sobre a $\mathrm{Cl}$.

A reflexão sobre a evolução da ciência da informação, suas relações com as ciências sociais e com o modelo moderno da ciência como um todo, é fundamental para a realização de pesquisas nessa área de forma a contribuir para uma ciência da informação que assuma, então, de forma definitiva, tanto sua natureza de ciência social quanto sua postura de ciência pós-moderna. (ARAÚJO, 2003, p.26-27).

Para o autor, a Cl não nasce como uma ciência social, mas traz em sua história essa bagagem, como em Ørom (2000), que traça a história da Cl desde a Idade Média, com a guarda do livro, para em seguida disponibilizá-lo. Muito ligada, inicialmente, à computação e mais tarde à recuperação da informação, ela estava, na verdade, atendendo a uma necessidade social, mesmo que, apenas, no campo científico. A sociedade precisa de memória para contar sua história, e a Cl estava preocupada em registrar essa informação, para em seguida recuperá-la.

Capurro (2003) acrescenta que a $\mathrm{Cl}$ nasce em meados do sec. XX com um paradigma físico, questionado por um enfoque cognitivo, idealista e individualista, sendo este, por sua vez, substituído por um paradigma pragmático e social. Traz, ainda, à superfície, a hermenêutica como paradigma da $\mathrm{Cl}$ no qual os usuários são capazes de interpretar suas necessidades [de informação] em relação a si próprios, a intermediários e ao sistema, e que essa interpretação se dá de acordo com o contexto social no qual estão inseridos. O contexto atual é a sociedade da informação, com novos problemas sociais, econômicos, técnicos, culturais e políticos, que devem ser enfrentados teórica e pragmaticamente por essa disciplina.

Em seu discurso, Capurro (2003) se apoia no conceito de Kuhn de paradigma como um modelo que nos permite ver uma coisa em analogia a outra, e identifica três paradigmas epistemológicos para a Cl: o físico, onde postula que há algo, um objeto físico, que um emissor transmite a um receptor, e este o interpreta de acordo com seus limites sociais pré-existentes; o cognitivo, em que a busca da informação se dá pela necessidade do usuário de solucionar uma situação-problema para a qual o conhecimento existente não é suficiente e que, portanto, os modelos mentais do usuário são transformados durante os processos informacionais utilizados na recuperação da informação; e o social, que integra o usuário como sujeito ativo do processo informacional, dotando-o de capacidade de objetivar suas necessidades de conhecimento e formular esquemas de busca, produção, transmissão, distribuição e consumo da informação, e sua aplicação em situações sociais concretas, contextualizadas.

O campo da $\mathrm{Cl}$ está constantemente mudando, requerendo dos pesquisadores uma revisão sistemática e, se necessário, uma redefinição de seus construtos fundamentais. Para tanto, Zins (2007a) realizou pesquisa durante os anos de 2003 a 2005, com 57 pesquisadores e acadêmicos de 16 países, que representam aproximadamente todos os maiores subcampos e aspectos importantes do campo da Cl. Para Zins (2007a), a Cl é o estudo das 
perspectivas da mediação, que incluem os aspectos cognitivo, social e tecnológico do conhecimento humano universal.

A pesquisa teve como respondentes autores como Barreto, Pinheiro, Saracevic, Buckland, Capurro, Hjorland. Em sua definição de $\mathrm{Cl}$, que pretende ser original e abrangente, o autor, sem mencionar, faz referência a Paul Otlet, quando aborda o meta-conhecimento do conhecimento humano, na perspectiva da $\mathrm{Cl}$ como mediadora do conhecimento humano universal.

O mapa do conhecimento desenvolvido por Zins (2007b) aproximou os conceitos existentes, organizando-os em grupos, com uma forte fundamentação teórica, e retratou o seu perfil num espaço de tempo. A $\mathrm{Cl}$, que vinha sendo discutida desde o fim da segunda guerra mundial, parece ter encontrado sua maturidade, e também contribui apresentando sua definição:

[...] a ciência da informação concentra-se no domínio universal. Está focada nas perspectivas do meta-conhecimento do conhecimento universal. Ciência da informação é o estudo das perspectivas de mediação do conhecimento humano universal [...] as perspectivas de mediação incluem aspectos cognitivos, sociais e tecnológicos, e condições que facilitem a disseminação do conhecimento humano da origem ao usuário (ZINS, 2007a, p. 339., tradução nossa).

Para Zins (2007b) a Cl é o estudo das perspectivas da mediação, que incluem os aspectos cognitivo, social e tecnológico do conhecimento humano universal.

\section{0 conceito de políticas públicas}

De acordo com Souza (2006), do ponto de vista teórico-conceitual, a política pública em geral, e a política social em particular, são campos multidisciplinares, que repercutem na economia e nas sociedades e comporta vários "olhares". Daí por que pesquisadores de tantas disciplinas - economia, ciência política, sociologia, antropologia, geografia, planejamento, gestão, ciências sociais aplicadas - partilham um interesse comum na área e têm contribuído para avanços teóricos e empíricos.

A política pública, para Souza (2006), é um campo holístico, isto é, uma área que situa diversas unidades em totalidades organizadas, tornando o campo território de várias disciplinas, teorias e modelos analíticos. A autora resume política pública como o campo do conhecimento que busca, ao mesmo tempo, "colocar o governo em ação" e/ou analisar essa ação e, quando necessário, propor mudanças no rumo ou curso dessas ações. Quando postas em ação, as políticas públicas são implementadas, ficando então submetidas a sistemas de acompanhamento e avaliação. Nesse sentido, Souza (2006) afirma que aquilo que o governo faz ou deixa de fazer é passível de ser formulado cientificamente, e analisado por pesquisadores independentes. Por fim, Souza (2006) extrai e sintetiza os seguintes elementos principais da política pública:

A política pública permite distinguir entre o que o governo pretende fazer e o que, de fato, faz; a política pública envolve vários atores e níveis de decisão, embora seja materializada através dos governos, e não necessariamente se restringe a participantes formais, já que os informais são também importantes; a política pública é abrangente e não se limita a leis e regras; a política pública é uma ação intencional, com objetivos a serem alcançados; a política pública, embora tenha impactos no curto prazo, é uma política de longo prazo; a política pública envolve processos subseqüentes após sua decisão e proposição, ou seja, implica também implementação, execução e avaliação (SOUZA, 2006, p.26).

Modelos explicativos foram criados no campo da política pública para que melhor se entenda como e por que um governo faz ou deixa de fazer alguma ação que repercutirá na vida dos cidadãos.

Segundo Lowi (1964), criador da mais conhecida tipologia sobre política pública, elaborada a partir da máxima "a política pública faz a política", diferentes tipos de políticas causam diferentes relações de poder entre os indivíduos e grupos, e diferentes formas de apoio e de rejeição. Tais relações podem ser preditas com base nos tipos de políticas públicas, as quais assumem quatro formatos: 
1. Políticas distributivas: decisões tomadas pelo governo para alocação de recursos a determinados grupos setoriais ou comunidades. Fornecem benefícios precisos a grupos sociais ou territoriais bem delimitados, sem nenhuma ligação direta e explícita com os custos, que recaem sobre a coletividade inteira, por meio da arrecadação fiscal. Geram impactos mais individuais do que universais, pois conferem privilégios a certos grupos sociais ou regiões, em detrimento do todo;

2. Políticas regulatórias: são normas impostas, que disciplinam aspectos da atividade social, regulam comportamentos e impõem obrigações. Condicionam o comportamento de certas categorias, impondo respeito a códigos, padrões de prestações e vínculos com a livre iniciativa. São mais visíveis ao público e envolvem burocracia, políticos e grupos de interesse;

3. Políticas redistributivas: distribuem recursos de qualquer natureza entre os grupos sociais na forma de transferência, isenções etc. Oferecem benefícios a largas camadas sociais, atingem maior número de pessoas e impõem perdas concretas e no curto prazo para certos grupos sociais, e ganhos incertos e futuros para outros, pois recursos são transferidos de uma parte da sociedade para outra. De execução complexa são, em geral, as políticas sociais universais, o sistema tributário, o sistema previdenciário;

4. Políticas constitutivas: implicam em mudanças estruturais. Lidam com procedimentos e alteram estruturas administrativas e governamentais. Estabelecem procedimentos para a adoção de decisões públicas e relações entre os vários aparatos do Estado. Por serem mais administrativas, atraem relativamente pouca atenção pública.

\section{Ciência da Informação e políticas públicas}

Seguindo nessa direção, e por compartilhar interesses comuns, trazemos o olhar da ciência da informação para o campo das Políticas Públicas. Freire (2008), por exemplo, afirma que a democratização do acesso à informação deveria ser vista como elemento fundamental nas políticas públicas de inclusão social. Entendemos, portanto, que a responsabilidade social da $\mathrm{Cl}$ tem uma relação intrínseca com o campo das políticas públicas.

Mas, o que é política? Segundo Bobbio et al. (2000) "política significa tudo que se refere à cidade, portanto, o que é urbano, civil, público, e até mesmo sociável e social”. Assim como a $\mathrm{Cl}$, as políticas públicas permeiam várias áreas do conhecimento, e também começam a ser discutidas após a segunda guerra mundial, quando foi introduzida como ferramenta nas decisões de governo como um produto da Guerra Fria. Robert McNamara, em 1948, estimulou a criação, nos Estados Unidos, de uma organização não-governamental interdisciplinar. A proposta de aplicação de métodos científicos às formulações e às decisões do governo sobre problemas públicos se expande, depois, para outras áreas da produção governamental, inclusive para a política social (SOUZA, 2006).

A Cl como ciência pós-moderna e que, conforme Wersig (1993) trata da "informação em ação" e, de acordo com Saracevic (1996), ressalta os papeis econômico e social das atividades de informação em direção ao desenvolvimento nacional e ao progresso social, pode caminhar com desenvoltura no campo das Políticas Públicas. Capurro (2003) reforça essa possibilidade quando situa a sociedade da informação como o contexto atual, com novos problemas sociais, econômicos, técnicos, culturais e políticos, que devem ser enfrentados teórica e pragmaticamente pela ciência da informação para, como sugere Barreto (1994), promover o desenvolvimento e o progresso do indivíduo, de seu grupo e da sociedade por meio da informação como mediadora do conhecimento.

Para González de Gomes (1999, p.69), a gestão da informação envolve:

[...] o planejamento, instrumentalização, atribuição de recursos e competências, acompanhamento

e avaliação das ações de informação e seus desdobramentos em sistemas, serviços e produtos [....] (GONZÁLEZ DE GÓMEZ, 1999, p.69 apud FREIRE, 2008).

De acordo com Souza (2006) as políticas públicas seguem um ciclo, composto pela formação da agenda, formulação, implementação, análise, avaliação e fiscalização. A ciência da informação possui ferramentas, teóricas e 
pragmáticas, que podem ser utilizadas em cada fase desse ciclo. A utilização dessas ferramentas está apoiada em Wersig e Neveling (1975) quando afirmam que a $\mathrm{Cl}$, com visão orientada para os fins, deve servir para o preenchimento de determinadas necessidades sociais:

1. Na formação da agenda utilizam-se a inteligência estratégica antecipativa e a inteligência competitiva, na medida em que a percepção de sinais fracos no ambiente sócio-políticoeconômico e a transformação de dados esparsos sobre esse contexto em conhecimento estratégico permitem apontar a direção a ser seguida nessa fase do ciclo;

2. Na formulação da política pública utiliza-se a gestão da informação, pois valendo-se de suas capacidades e recursos informacionais, o Estado pode administrar a informação como um recurso estratégico fundamental para uma eficaz adaptação às mudanças ambientais que requerem pronta ação governamental; e

3. Nas fases de implementação, análise, avaliação e fiscalização são utilizadas a gestão da informação e do conhecimento posto que, nessas fases, são necessários o monitoramento informacional da ambiência e seu processamento na forma de experiências e práticas documentadas e explicitadas, tanto nos aspectos tecnológico, ambiental, social, econômico e emancipatório, quanto no de resultados concretos alcançados.

Nessa direção, as instituições do Estado, ao adotarem essas ferramentas, estarão aptas a monitorar o ambiente econômico e social, identificar as mudanças ambientais e contribuir na formação da agenda e na formulação de políticas públicas consistentes que atendam à demanda da população.

\section{Considerações finais}

Pretendeu-se, neste artigo, mostrar a aproximação existente entre a Ciência da Informação, focando sua responsabilidade social, e o campo das políticas públicas, trazendo a compreensão de que as relações existentes entre as duas disciplinas são complementares, posto que aquela oferece a essa recursos, ferramentas e capacidades para tomada de decisões relacionadas a escolhas e caminhos que vão impactar nos rumos do desenvolvimento da economia e da sociedade.

Portanto, a responsabilidade social da $\mathrm{Cl}$ e sua práxis residem, também, no oferecimento desse conjunto de capacidades como recurso legítimo para integrar e coordenar a heterogeneidade dos recursos informacionais existentes em uma sociedade para, por meio de políticas públicas, permitir ao ser humano construir a si mesmo e o seu mundo, de forma livre e autônoma, e transformar a realidade na direção do desenvolvimento político, econômico e social, pois, conforme Saviani (1989, p.66), "o dominado não se liberta se ele não vier a dominar aquilo que os dominantes dominam. Então, dominar o que os dominantes dominam é condição de libertação".

Finalmente, de acordo com Alvares e Araújo Júnior (2010), como toda ciência, a Ciência da Informação segue seu curso histórico, adaptando-se, evoluindo e incorporando novos conceitos e práxis com a finalidade de cumprir sua responsabilidade social levando a informação a quem dela precisa.

$\mathrm{A} \mathrm{Cl}$, como ciência pós-moderna preocupada com os seres humanos e com o uso que fazem do conhecimento, é uma ciência que busca facilitar o acesso ao conhecimento produzido por todas as outras disciplinas para que seja adequadamente usado e que possa levar a mudanças e transformações sociais. As unidades de informação sempre tiveram funções sociais bem definidas, antes preservando o conhecimento, e mais tarde tornando-o acessível a todos.

Dos escribas aos ciber-bibliotecários perpassa a responsabilidade social da ciência da informação. Logo, pensar a $\mathrm{Cl}$ como disciplina possível para construção de Políticas Públicas capazes de alavancar o desenvolvimento econômico e de promover a inclusão social é reafirmar seu caráter humanista, é colocá-la em lugar privilegiado no campo das ciências sociais aplicadas. 


\section{Referências}

ALVARES, Lillian; ARAÚJO JÚNIOR, Rogério Henrique de. Marcos históricos da ciência da informação: breve cronologia dos pioneiros, das obras clássicas e dos eventos fundamentais. TransInformação, v. 22, n. 3, p. 195205, set./dez. 2010. Disponível em: http://revistas.puc-campinas.edu.br/transinfo/ . Acesso em: 12 jul. 2011.

ARAÚJO, Carlos Alberto Ávila. A ciência da informação como ciência social. Ciência da Informação, Brasília, v.32, n.3, p. 21-27, set./dez. 2003. Disponível em: http://www.scielo.br/pdf/ci/v32n3/19020.pdf. Acesso em: 18 maio 2011.

BARRETO, Aldo de Albuquerque. A questão da informação. São Paulo em Perspectiva, São Paulo. v.8, n.4, 1994. Disponível em: http://www.e-iasi.org/cinfor/quest/quest.htm. Acesso em: 20 jun. 2011.

BATES, Marcia J. The invisible substrate of Information Science. Journal of the American for Information Science, v.50, n.12, p.1043-1050, 1999. Disponível em: http://gseis.ucla.edu/faculty/bates/substrate.html . Acesso em: 21 abr. 2011.

BOBBIO, Norberto; MATTEUCCI, Nicola; PASQUINO, Gianfranco. Dicionário de política. 5.ed. Brasília : UnB, 2000. v.2, p.954.

BELKIN, N.J. Information concepts for information science, 1993. Disponível em: http://aprender.unb.br/course/view.php?id=3530. Acesso em: 26 mar. 2011.

BORKO, H. Information Science: What is it?. American Documentation, v. 19, n.1, p. 3-5, Jan. 1968. Disponível em: Disponível em: http://aprender.unb.br/course/view.php?id=3530. Acesso em: 26 mar. 2011.

BRIET, Suzanne. Qu'est-ce que la documentation?. 1951. Disponível em:

http://martinetl.free.fr/suzannebriet/questcequeladocumentation/. Acesso em: 20 maio 2011.

CAPURRO, Rafael. Epistemologia e ciência da informação. In: ENCONTRO NACIONAL DE PESQUISA EM CIÊNCIA DA INFORMAÇÃO, 5., 2003, Belo Horizonte. Anais... Belo Horizonte: ENANCIB, 2003. Disponível em: http://www.capurro.de/enancib p.htm. Acesso em: 28 abr. 2011.

FREIRE, Gustavo Henrique de Araújo. Construção participativa de instrumento de política pública para gestão e acesso à informação. Perspectivas em Ciência da Informação, v.13, n.3, set./dez. 2008. Disponível em: http://www.scielo.br/scielo.php?script=sci arttext\&pid=S1413-99362008000300013. Acesso em: 16 jun. 2011.

INGWERSEN, Peter. Information science in context. In: Information retrieval interaction. London, Taylor Graham Pub. 1992. Chapter 1.

LEVIE, Françoise. The man who wanted to classify the world. 2002. Sinopse. Disponível em:

http://www.kk.org/truefilms/archives/2007/10/the man who wan.php. Acesso em: 21 maio 2011.

LOWI, Theodor J. American business, public policy, case-studies, and political. World Politics. v. 16. n. 4, p. 677715, jul. 1964.

$\varnothing \mathrm{ROM}$, Anders. Information science, historical, changes and social aspects: a Nordic outlook. Journal of Documentation, v. 56, n.1, p.12-26, Jan. 2000.

POPPER, Karl. A lógica da pesquisa científica. São Paulo: Cultrix, 1972.

ORTEGA, Cristina Dotta. Surgimento e consolidação da documentação: subsídios para compreensão da história da ciência da informação no Brasil. Perspectivas em Ciência da Informação, v.14, nesp, p.59-79, 2009. Disponível em: http://portaldeperiodicos.eci.ufmg.br/index.php/pci/article/viewFile/899/626. Acesso em: 20 maio 2011.

SANTOS, Boaventura de Sousa. Um discurso sobre as ciências na transição para uma ciência pós-moderna. Estudos Avançados, v.2, n.2, p. 46-71, maio/ago. 1988. Disponível em: http://www.scielo.br/scielo.php?script=sci arttext\&pid=S0103-40141988000200007. Acesso em: 15 abr. 2011.

SARACEVIC, Tefko. Interdisciplinary nature of Information Science. Ciência da Informação, v. 24, n.1, 1995. Disponível em: http://dici.ibict.br/archive/00000598/01/natureza interdisciplinar.pdf. Acesso em: 3 abr. 2011. 
SARACEVIC, Tefko. Ciência da informação: origem, evolução e relações. Perspectivas em Ciência da Informação, v.1, n.1, p.41-62, jan./jun. 1996.

SAVIANI, Dermeval. Escola e democracia: teorias da educação, curvatura da vara, onze teses sobre educação e política. São Paulo: Cortez: Autores Associados, 1989.

SMIT, Johanna W.; TÁLAMO, Maria de Fátima; KOBASHI, Nair Y. A determinação do campo científico da Ciência da Informação: uma abordagem terminológica. DataGramaZero: Revista de Ciência da Informação, v.5, n.1, fev. 2004. Disponível em: http://www.dgz.org.br/fev04/Art 03.htm. Acesso em: 01 jun. 2011

SOUZA, Celina. Políticas públicas: uma revisão da literatura. Sociologias, Porto Alegre, v.8, n.16, p.20-45, jul./dez. 2006.

TARAPANOFF, Kira. Informação, conhecimento e inteligência competitiva. In: informação e conhecimento. Brasília : IBICT, UNESCO, 2006. p.19-36.

(Org). Inteligência,

WERSIG, Gernot. Information Science: the study of postmodern knowledge usage. Information Processing \& Management., v. 29. n. 2, p. 229-239, 1993.

WERSIG, G.; NEVELING, U. Os fenômenos de interesse para a ciência da informação, 1975. Tradução do inglês por Tarcísio Zandonade. Disponível em:

http://www.alvarestech.com/lillian/GestaoDalnformacao/Rogerio/WersigNeveling.pdf. Acesso em: 18 jun. 2011. 1975.

. The phenomena of interest to information science. The Information Scientist. v. 9, n. 4, p.127-140,

ZINS, Chaim. Conceptions of Information Science. Journal of the American Society for Information Science and Technology, v.58, n.3, p. 335-350, 2007a.

Knowledge map of Information Science. Journal of the American Society for Information Science and Technology, v. 58, n.4, p.526-535, 2007b. 


\section{Datos de los autores}

\section{Marcia Mazo Santos}

Mestre em Gestão do Conhecimento e da Tecnologia da Informação pela Universidade Católica de Brasília, doutoranda em Ciência da Informação pela Universidade de Brasília, Brasil. Diretora da Biblioteca do Tribunal Regional Federal da Primeira Região.

marciamazo@gmail.com

\section{Jair Cunha Cardoso Filho}

Doutorando em Ciência da Informação na Universidade de Brasilia - UnB. Possui graduação em Administração pela AEUDF(1988) e Mestrado em Ciência da Informação pela Universidade de Brasília (2003), com foco em Gestão de Competências. Especialista em Administração (1997) e em Administração Legislativa (2005) pela UnB, e em Legislativo e Políticas Públicas pelo Cefor/CD. É Consultor Técnico Legislativo da Câmara Legislativa do Distrito Federal. Tem experiência na área de Administração, com ênfase em Planejamento Estratégico, Gestão de Competências e Gestão do Conhecimento. É coordenador do Comitê de Planejamento Estratégico Institucional da Câmara Legislativa do DF. Tem interesse de pesquisa nessas áreas e em Gestão da Informação, Inteligência Competitiva e Informação e Políticas Públicas.

jairim01@gmail.com

Recebido - Received: 2011-12-04

Aceito - Accepted: 2012-03-31

\section{(cc) BY-NC-ND}

This work is licensed under a Creative Commons Attribution-Noncommercial-No Derivative Works 3.0 United States License.

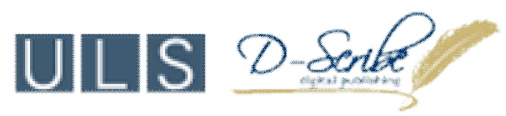

This journal is published by the University Library System of the University of Pittsburgh as part of its $\underline{D-S c r i b e}$ Digital Publishing Program and is cosponsored by the University of Pittsburgh Press. 